Journal of Accident and Emergency Medicine 1995 12, 189-190

\title{
A radiological review of cervical spine injuries from an Accident and Emergency department: has the ATLS made a difference?
}

\author{
S.H. PALMER \& M. MAHESON
}

Department of Orthopaedics and Trauma, Cardiff Royal Infirmary, Cardiff, South Wales, UK

\section{SUM MARY}

The importance of visualizing the entire cervical spine on radiological examination in patients with cervical trauma is well known. A review of the cervical films of 98 patients attending an accident and emergency (A\&E) department was undertaken in order to assess the adequacy of imaging. It was found that $33.7 \%$ of the films were not sufficient to exclude fracture or dislocation of the cervical spine. The number of patients with inadequate views was significantly reduced when an advanced trauma life support trained senior doctor was involved.

Keywords: cervical spine, cervicothoracic junction, radiograph

\section{INTRODUCTION}

The early diagnosis of injury to the cervical spine is essential as the consequences of delayed diagnosis can be devastating. ${ }^{1}$ There is no recognized treatment that is effective in reversing the neurological sequelae of cord damage once it has occurred (although high-dose steroids may be beneficial in the acute situation).

Clinical assessment and radiological imaging are used to exclude such diagnoses. Once the suspicion of the physician has been aroused it is essential to have an adequate view of the entire cervical spine.

The aim of this study was to assess the adequacy of imaging of the cervical spine in patients with cervical trauma in a busy A\&E department.

Correspondence:

S.H. Palmer,

Registrar in

Orthopaedics, 8

Hanover Terrace,

Camden, Bath

BAI 6LJ, UK

\section{PATIENTS AND METHODS}

A retrospective review of cervical spine radiographs was undertaken in 98 patients who attended the Cardiff Royal Infirmary A\&E department with injuries to the neck. Multiple trauma patients who were necessarily admitted to hospital were not included, as all patients in this study were discharged on the same day.

The notes and radiographs of 98 patients over a 3-month period were reviewed.

A set of radiographs was deemed to be adequate if the following views were present.

(1) An anterio-posterior view.

(2) An open-mouth view with visualization of the odontoid peg and atlanto-axial joints.

(3) A lateral view showing C1 to the top of T1.

If such views were not adequate, but other imaging was performed in order to visualize the entire cervical spine (e.g. cervical screening, swimmers' views), then these were accepted.

\section{RESULTS}

The total number of radiographs reviewed was 98 (50\% female and $50 \%$ male). The average age of patients was 30.3 years (males, 34.7 years; females, 25.9 years), and the injuries were predominantly whiplash, rugby and head-injuries with associated neck trauma. All patients were seen initially by the A\&E senior house officer (SHO). A total of 19 patients were also seen by a more senior member of staff (A\&E senior registrar/consultant or orthopaedic registrar), all of whom were trained in advanced trauma life support (ATLS).

According to the above criteria, 33 patients $(33.7 \%)$ had inadequate views of the cervical spine. These were either inadequate lateral cervical spine views $(19.6 \%)$ or inadequate open-mouth views $(\mathbf{1 4 . 1 \% ) . ~ T h e ~ n u m b e r ~ o f ~ p a t i e n t s ~ w i t h ~ a d e q u a t e ~}$ views was $65 / 98(66.3 \%)$. The number of swimmers' views requested was $9 / 98$ (9.1\%), all of which were adequate. The number of cases with inadequate imaging in which an ATLS-trained senior physician was consulted was $2 / 33(6.1 \%)$ 


\section{S. H. Palmer \& \\ M. Maheson}

The number of cases with adequate views in which a senior physician was involved was 11/65 (16.9\%).

\section{DISCUSSION}

There is good evidence that the three standard view radiographs listed above can be safely used to exclude cenvical spine fracture or dislocation (combined with the use of CT scanning when such views are incomplete). ${ }^{2,3}$

This study highlights the fact that a large proportion of neck injury patients who are awake and cooperative are being discharged without adequate imaging of the cervical spine (33.7\% of cases). This is of particular importance in such a young sub-group of the population (mean age 30.3 years).

Previous studies have shown the presence of cervical spine fractures in conscious patients with neck pain only, and also in patients who are totally asymptomatic. ${ }^{4,5}$

These results also indicate the problems that the relatively inexperienced A\&E SHO faces when dealing with patients in the resuscitation room. Such patients are often unconscious or uncooperative with multiple injuries. The long-term complications incurred by such patients with insufficient radiology are obvious.

None of the patients in this study who were discharged with inadequate views of the cervical spine returned to the department with serious complications.

It is suggested, on the basis of the results of this study, that in situations where a senior ATLStrained doctor is involved there is a very low incidence of inadequate radiology. It appears that the A\&E SHO may not have sufficiently developed skills to assess the cervical spine views correctly, and may not recognize the importance of complete cervical spine radiographs.

A similar study performed prior to the introduction of the advanced trauma life support ATLS course in $1987^{6}$ found that $42 \%$ of that patients had inadequate radiology. These findings are similar to the results obtained in our study.
Although there appears to be an improvement in the number of patients with inadequate radiology, it is only slight. It would therefore appear that the introduction of the ATLS course in $1988^{7}$ (with its recommendations regarding radiology of the cervical spine $)^{8}$ has not had a great impact on the relatively junior A\&E SHO. However, none of the SHOs were trained in ATLS, although all the senior staff involved were so trained.

We therefore suggest, that A\&E SHOs should be given specific tuition in radiology of the cervical spine, perhaps with more supervision by ATLStrained senior staff, especially during the early stages of their posts.

\section{ACKNOWLEDGEMENTS}

We would like to thank MrP. Richmond for allowing us access to the notes and radiographs from the A\&E department, and MrR. Evans for his guidance with regard to the review of the literature.

\section{REFERENCES}

1. Gutmann L. (1973) Spinal Cord Injuries Comprehensive Management and Research, first edition, pp. 136-142. Blackwell Scientific Publications, Oxford.

2. Ross S. E. (1987) Clearing the cervical spine: initial radiologic evaluation. The Journal of Trauma 27, 1055-1057.

3. Freemyer B. (1989) Comparison of five view and three view cervical spine series in the evaluation of patients with cervical trauma. Annals of Emergency Medicine 18, 18-20.

4. Kreipke D.L. (1989) Reliability of indications for cervical spine films in trauma patients. Journal of Trauma 29, 1438-1439.

5. Gisbert V.L. (1989) Incidence and diagnosis of C7-I1 fractures and subluxations, in multiple trauma patients: evaluation of the ATLS guidelines. Surgery 106, 702709.

6. Bryan A.S.(1989) A review of cervical spine $X$-rays from a casualty department. Journal of the Royal College of Edinburgh 33,143-145.

7. Editorial (1993) Advanced trauma life support. Injury 24, 147-148.

8. American College of Surgeons (1988) Advanced Trauma Life Support Manual. American College of Surgeons, Chicago, Illinois. 